\title{
sciendo
}

\section{Circulating Inflammatory Biomarkers and Endocrine Responses to Exercise in Female Soccer Players}

\author{
by \\ Grażyna Janikowska1, Aleksandra Kochańska-Dziurowicz², Ilona Pokora3 , \\ Aleksandra Żebrowska
}

The objective of the study to determine the effects of graded exercise on the cytokines and insulin-like growth factor-1 (IGF-1), growth hormone ( $h G H)$, testosterone (T), and cortisol (C) concentrations in the peripheral blood of female soccer players, and to evaluate if increased inflammatory biomarkers were related to these hormones and performance variables. Sixteen female soccer players $(N=16$, age $19.3 \pm 2.3$ years) participated in this study. Blood samples were collected at three time points: pre-exercise, post-exercise, and in the 15th minute of recovery, to evaluate morphological and biochemical variables. The relative expression of IL-6 (interleukin 6) and serum concentrations of the cytokines were increased in the recovery period compared to pre-exercise levels ( $p=0.03$ and $p=0.005$, respectively). There was a significant effect of exercise on serum $h G H$ level $(p<0.001), T / C$ ratio $(p=0.001)$, and $C$ level $(p=0.02)$. Positive correlations were found between: post-exercise IL-1 $\beta$ (interleukin 1 beta) and IL-6 $(R=0.84, p=0.000$ ), and the IL-6 and TNF- $\alpha$ (tumor necrosis factor alpha) gene expression during recovery $(R=0.65, p=0.009)$, and serum IL$1 \beta$ post-exercise and maximal power $(R=0.68 ; p=0.004)$. Exercise-induced serum $C$ levels positively correlated with IGF-1 levels $(R=0.52 p=0.05)$. Negative associations were revealed between post-exercise T/C ratio and IGF-1 $(R=-$ $0.58, p=0.03)$ and serum free $T$ and $I L-\beta(R=-0.56, p=0.04)$ levels. The low level of pre-exercise genes and protein of the IL-1 $\beta, I L-6$ and TNF- $\alpha$ indicate a lack of inflammation signs in the female soccer players. This study shows significant effects of exercise on hormone levels and pro-inflammatory markers, which could be used to identify the role of female sex steroids on the immune function.

Key words: cytokine, hormones, female soccer players, exercise performance.

\section{Introduction}

The increasing popularity of female soccer developed an interest regarding their physiology and adaptive responses to exercise. Especially to exercise-induced secretion of pro-inflammatory cytokines and steroid hormones during different training loads and competition (Roli et al., 2018; Edwards et al., 2013; Walsh et al., 2011). There is extensive literature regarding the variation of different biological variables, resulting from physical and mental stress of professional athletes (Ostrowski et al., 1999; Rowel et al., 2018; Oliveira et al., 2009). The accumulated effect of exercise on systemic inflammation has been studied widely in male soccer players (Bizzini and Dvorak, 2015). However, the knowledge about the relation between blood cytokine gene expression, anabolic and catabolic hormone concentrations and the performance variables in female athletes is still inadequate (Gjevestad et al., 2015; Larsen et al., 2018; Gillum et al., 2011).

Cytokines, including interleukin 1 beta (IL-1 $\beta$ ), interleukin 6 (IL-6) and tumor necrosis factor alpha (TNF- $\alpha)$, are important mediators of acute phase response to muscle damage and

\footnotetext{
1 - Department of Analytical Chemistry, Medical University of Silesia, Katowice, Poland.

2 - Silesian College of Medicine in Katowice, Poland.

3 - Institute of Sport Sciences, Academy of Physical Education, Katowice, Poland.
} 
muscle contractions (Ostrowski et al., 1999, Walsh et al., 2011; Scheller et al., 2011). The relationship between the mentioned cytokines is well-known; where IL-6 inhibits the expression of TNF- $\alpha$ and IL-1 $\beta$. In response to exercise IL- 6 is produced in larger amounts than the other cytokines (Petersen and Pedersen, 2006) and a positive correlation between exercise intensity and plasma IL-6 concentration has also been reported (Ostrowski et al., 2000).

Numerous studies have shown different levels of blood cytokines depending on the type and intensity of exercise and training status (Petersen and Pedersen, 2006; Meckel et al., 2011). Additionally, during exercise, cytokine secretion is related to endocrine and paracrine factors (Pedersen and Febbraio, 2008; Meckel et al., 2011). Given the relationship between hormones and immunity, little research has investigated the role of female sex steroids on the immune function (Schuurs and Verheul, 1990; Giraldo et al., 2011; Roli et al., 2018). A greater anti-inflammatory status has been reported in response to contraceptive use and was parallel with lower estrogens concentrations. Cortisol, prolactin, and IL-6 seem to be involved in gender-inflammatory differences (Gillum et al., 2011), and in the restoration of homeostasis (Jürimäe et al., 2011). It has been hypothesized that, in female athletes exercise may lead to an higher increase of anabolic hormones in response to exerciseinduced pro-inflammatory cytokines (IL-6, TNF $\alpha$ ) as well as an higher anti-inflammatory cytokine level compared to reference norms in a healthy population (Roli et al., 2018).

High-intensity exercise has been known to increase circulating IGF-1, one of the most important anabolic factors, that takes place following exercise below and above the anabolic threshold (Copeland and Heggie, 2008; Żebrowska et al., 2009; Hackney et al., 2016). Exercise-associated increase in testosterone (T) and $\mathrm{T} / \mathrm{C}$ ratio, might potentially influence muscle protein synthesis, anti-inflammatory properties, and GH/IGF-1 axis response to exercise (Chmura et al., 2019, Oliveira et al., 2009). It has been hypothesized that testosterone induced a reduction in circulating IGF-1 levels and may have a direct, IGF-1 and GH-independent effect on muscle growth. Importantly, the balance between the anabolic and inflammatory response to exercise has been suggested as a good predictor of the effectiveness of exercise on health benefits (Gregory et al., 2013; Jürimäe et al., 2011; Smith, 2000).

The peripheral inflammatory response to intense exercise has been extensively studied in male soccer players. In contrast, relatively little is known concerning the hormonal changes that occur following high intensity exercise and its implication on the potential anti-inflammatory effects in female athletes (Soligard et al., 2008; Andersson et al., 2010; Souglis et al., 2015).

Therefore, the aim of this study was to evaluate the gene expression and serum concentrations of IL-1 $\beta$, IL6 and TNF- $\alpha$ and insulin-like growth factor-1 (IGF-1), growth hormone (hGH), testosterone (T), and cortisol levels before and after a graded treadmill exercise to volitional exhaustion in female soccer players. The other objective was to analyze the relationships between cytokines and hormones and aerobic performance parameters of female soccer players.

\section{Methods}

\section{Participants}

Female soccer players $(\mathrm{N}=16)$, from the $\mathrm{I}^{\mathrm{st}}$ division of the Polish soccer league participated in the study (age: $19.3 \pm 2.3$ years, body mass: $59.4 \pm$ $7.5 \mathrm{~kg}$, body height: $167 \pm 1 \mathrm{~cm}$, body mass index (BMI): $21.3 \pm 2.1 \mathrm{~kg} / \mathrm{m}^{2}$ ). Each participant had a minimum of 3 years training experience with a mean training status of approximately $6.7 \pm 4.4$ years. They were instructed to abstain from exercise, caffeine, alcohol, vitamins and any medicines' for 24-h prior to the exercise protocol. For the entire duration of the experiment, they were placed on a mixed isocaloric diet.

The study design was approved by the Bioethic Committee of the Medical University of Silesia (consent No. KNW/0022/KB1/122/I/09) and conformed to the standards set by the Declaration of Helsinki.

\section{Maximal graded exercise test}

All athletes performed an progressive exercise test which allowed to determine maximal oxygen uptake $\left(\mathrm{VO}_{2 \max }\right)$ and maximal power output $\left(\mathrm{P}_{\max }\right)$. The graded treadmill exercise test (HP/Cosmos-Pulsar, Germany) was performed to volitional exhaustion. The exercise protocol started at a speed of $6 \mathrm{~km}$ per hour, and was 
increased every 3 min by $2 \mathrm{~km}$ per hour until a maximal individual load was reached. Oxygen uptake $\left(\mathrm{VO}_{2}\right)$, pulmonary minute ventilation $(\mathrm{VE})$, and heart rate (HR) were continuously monitored from the $6^{\text {th }}$ minute before the onset of the test and during the exercise using a respiratory analyzer (Matalyzer 3B, Cortex, Germany) and a telemetric HR monitor (PE-3000 Sport-Tester, Polar Inc. Finland). Before the exercise protocol, body mass was recorded and the body mass index was calculated (InBody Data Management System, UK).

\section{Biochemical analyses}

Blood samples were collected from the cubital vein at three time points: 1 ) between 08.00 and $09.00 \mathrm{~h}$ at rest (pre-exercise), 2) immediately after the cessation of exercise (post-exercise), and 3) after 15 minutes of recovery (recovery). All serum samples were left to clot at room temperature for $30 \mathrm{~min}$ and centrifuged for $15 \mathrm{~min}$ at $1000 \times \mathrm{g}$ and kept frozen at $-80^{\circ} \mathrm{C}$ (for a period not longer than eight months, without repeated freezing) until analyses for concentration of IGF-1, IGFBP-3, hGH, T, freeT, C, TGF- $\beta$ ), and interleukins (Il-6 and Il-1 $\beta$ ) were performed. Blood samples were also collected in order to examine blood morphology and the gene expression of and IL-1 $\beta$, IL6, TNF- $\alpha$. The whole blood intended for RNA isolation was frozen at liquid nitrogen temperature until use. The complete blood count was determined on the same day using ABX MICROS ES-60 hematology analyzer (HORIBA Medical). The isolated RNA (Chomczyński and Sacchi, 1987) was determined with a spectrophotometry procedure GeneQuant pro Amersham Biosciences $(\lambda=260,280$ and 320 $\mathrm{nm})$. Gene expression was estimated using the RT-qPCR reaction in the Opticon ${ }^{\mathrm{TM}}$ DNA Engine Continuous Fluorescence Detector (MJ Research, Watertown, MA) under standard thermal conditions according to Qiagen's instructions. The reaction mixture contained the QuantiTect ${ }^{\circledR}$ probe RT-PCR kit with RT enzyme, total RNA from PBMC (peripheral blood mononuclear cells) and $A C T B$ - $\beta$-actin (Hs 99999903_mL) or GAPDH Glyceraldehyde-3-phosphate dehydrogenase (Hs99999905_mL) or IL-1 $\beta$ (Hs00174097_mL) or IL-6 (Hs174131_mL) or TNF- $\alpha$ (Hs00174128_mL) primers. The specificity of amplification was assessed based on the melting curve. The expression of the above mentioned genes for each athlete was determined in triplicate.

The concentration of IL-1 $\beta$, IL-6, and TNF$\alpha$ was measured in the serum using the Quantikine ELISA Kits at standard procedure (R\&D Systems, Inc.). The IL-1 $\beta$, IL-6, and TNF- $\alpha$ detection limits were 1.0, 0.7, and 1.5 pg per $1 \mathrm{~mL}$, respectively. The concentration of insulin-like growth factor-1 (IGF-1) was determined with the IGF1-RIACT kit (Cisbio, France) and growth hormone (HGH) levels were determined with the hGH-RIACT kit (Cisbio, France). The insulin-like growth factor-binding protein 3 (IGFBP-3) concentration was also assessed with the IRMA method using the IGFBP-3-IRMA-CT KIPB1014 kit (Biosource Europe SA Company, England). The concentrations of testosterone (T), free testosterone (freeT), and cortisol (C) in blood serum were determined by radioimmunoassay (RIA) using TESTO-CT-2 (Cisbio, France) and CORT-CT-2 (Cisbio, France) kits per manufacturer's instructions.

Blood lactate concentrations were determined using the Biosen C_line method (EKF Diagnostic GmbH, Germany); acid-base balance was also analyzed (RapidLab 348; Bayer Diagnostics, Germany). Changes in plasma volume were taken into account during the evaluations.

\section{Statistical analysis}

The statistical analysis of the obtained results were performed using Statistica 13.1 software (StatSoft, Inc. Tulsa, OK, USA). Data distribution was assessed with the KolmogorovSmirnov test for normality. The arithmetic mean and the standard deviation (SD) were calculated for age, training experience, $\mathrm{VO}_{2}, \mathrm{VO}_{2 \max }, \mathrm{HR}$, $\mathrm{HR}_{\max }, \mathrm{V}_{\mathrm{E}}, \mathrm{P}_{\max }, \mathrm{BMI}$, cytokine protein and hormone concentrations. The data were analyzed by one-way ANOVA followed by the StudentNewman-Keuls test when appropriate. Differences between the genes expression and their significance were calculated using REST software (Pfaffl et al., 2002) calculating 2 - $\Delta \Delta c t$. Pearson correlation coefficients were analyzed to determine the relationships between cytokines and the physiological variables of exercise performance. Spearman's rank correlation coefficient was used for non-normal distributed data (ie., gene expression). Statistical significance was set at $p<0.05$. 


\section{Results}

The physiological performance variables and the blood variables of female soccer players before and after the intense graded treadmill exercise are presented in Table 1.

Significant differences between preexercise and post-exercise WBC count $(p<0.000)$ and a tendency for higher blood HGB $(p=0.054)$ concentration were observed (Table 1 ).

The relative expression of $I L-1 \beta, I L-6$, and TNF- $\alpha$ genes (compared to housekeeping gene $G A P D H)$ calculated according to the time of the experiment (pre-exercise data was basal), is presented in Table 2. The ANOVA revealed a significant effect of exercise on serum IL-6 concentrations $(\mathrm{F}=17.8 p=0.001)$, but not on IL$1 \beta$ and TNF- $\alpha(p>0.05)$ levels. A significant increase was confirmed in post hoc analyses between the pre-exercise and recovery IL-6 levels $(p=0.005)$ (Figure 1).

A significant effect of exercise on serum $\mathrm{C}$ levels $(\mathrm{F}=8.15, p<0.001)$ and $\mathrm{T} / \mathrm{C}$ ratio $(\mathrm{F}=9.15, p$ $<0.001)$ were found. Exercise significantly increased serum C levels immediately after exercise $(p<0.02)$ and during $15 \mathrm{~min}$ of recovery $(p<0.001)$ (Table 3). A significant increase was observed in post-exercise serum $\mathrm{T} / \mathrm{C}$ ratio $(p<$ $0.001)$ and hGH $(p<0.000)$ levels compared to preexercise levels. The ANOVA revealed a nonsignificant trend for higher IGF-1 $(p=0.10)$ and freeT $(p=0.18$ ) levels after exercise compared to pre-exercise levels (Table 3).
As for the relationship between all of the obtained results, the post-exercise gene expression of $I L-1 \beta$ was positively correlated with postexercise $I L-6(R=0.84, p=0.000)$. The recovery $I L-$ $1 \beta$ gene expression was in an inverse relation with the age of the players $(\mathrm{R}=-0.56, p=0.038)$ and $H R_{\max }(\mathrm{R}=-0.67, p=0.013)$. The recovery $I L-6$ was found to significantly correlate with the recovery TNF- $\alpha$ gene expression $(\mathrm{R}=0.65, p=0.009)$. Furthermore, post-exercise serum concentration of IL-1 $\beta$ showed correlations with $\mathrm{P}_{\max }$ (Figure 2 A) and BMI (Figure 2 B); the higher the intensity of maximal exercise (and BMI) of the players, the higher the serum IL1 $\beta$ concentration. Similarly to gene expression relation, the recovery IL1 $\beta$ serum concentration also inversely correlated with the age of the players (Figure $2 \mathrm{C}$ ). Pre-exercise serum IL-6 concentration was inversely correlated with training experience of the female soccer players (Figure 2 D), ie., the longer the training period, the lower the pre-exercise serum level of IL6.

There were positive correlations between hGH levels and $\mathrm{VO}_{2 \max }(\mathrm{R}=0.50 p=0.05)$ and $\mathrm{a}$ negative correlation between $\mathrm{VO}_{2}$ max and $\mathrm{BMI}(\mathrm{R}$ $=-0.68 p=0.01)$. Post-exercise $\mathrm{C}$ and $\mathrm{hGH}$ correlated positively with IGF-1 levels $(\mathrm{R}=0.52, p$ $=0.05$ and $\mathrm{R}=0.60, p=0.02$, respectively). Moreover, the recovery $\mathrm{T} / \mathrm{C}$ ratio was in an inverse relation with IGF-1 levels. Immediately post-exercise freeT levels correlated negatively with serum IL-1 $\beta$ levels $(\mathrm{R}=-0.56, p=0.03$ ). The absence of other correlations between hormones and cytokines were revealed in female soccer players.

\begin{tabular}{|c|c|c|c|}
\hline \multicolumn{4}{|c|}{$\begin{array}{c}\text { Table } \mathbf{1} \\
\text { Physiological variables and blood variables in response of graded exercise } \\
\text { of examined female soccer players (mean } \pm S D) .\end{array}$} \\
\hline Variables & Pre-exercise & Post-exercise & $p$ \\
\hline $\mathrm{VO}_{2}\left[\mathrm{~mL} \mathrm{~kg}^{-1} \mathrm{~min}^{-1}\right]$ & $0.39 \pm 0.09$ & $43.8 \pm 5.0$ & 0.000 \\
\hline $\mathrm{VE}_{\max }\left[\mathrm{mL} \mathrm{min}{ }^{-1}\right]$ & $11.10 \pm 2.29$ & $92.0 \pm 10.8$ & 0.000 \\
\hline HR [bpm] & $91.63 \pm 17.96$ & $195.07 \pm 7.61$ & 0.000 \\
\hline WBC $\left[10^{3} \mathrm{~mm}^{-3}\right]$ & $6.69 \pm 1.29$ & $11.24 \pm 2.04$ & 0.000 \\
\hline $\mathrm{RBC}\left[10^{6} \mathrm{~mm}^{-3}\right]$ & $4.54 \pm 0.22$ & $4.63 \pm 0.24$ & 0.070 \\
\hline $\mathrm{HGB}\left[\mathrm{g} \mathrm{dL}^{-1}\right]$ & $13.83 \pm 0.90$ & $14.00 \pm 0.94$ & 0.054 \\
\hline HCT [\%] & $40.84 \pm 2.75$ & $41.74 \pm 2.68$ & 0.059 \\
\hline $\mathrm{LA}\left[\mathrm{mmoL} \mathrm{mL}^{-1}\right]$ & $1.04 \pm 0.01$ & $7.67 \pm 2.8$ & 0.000 \\
\hline $\mathrm{pH}$ & $7.41 \pm 0.03$ & $7.30 \pm 0.9$ & 0.010 \\
\hline \multicolumn{4}{|c|}{$\begin{array}{c}\mathrm{VO}_{2} \text { - oxygen uptake; VE-pulmonary minute ventilation; HR-heart rate; WBC-number of white blood cells; } \\
\mathrm{RBC} \text { - number of red blood cells; HGB-haemoglobin; HCT-haematocrit; LA-blood lactate concentration; } \\
\text { p-significant differences between pre-exercise and post-exercise value. }\end{array}$} \\
\hline
\end{tabular}


Table 2

Transcriptional activity of IL1- $\beta, I L-6$ and TNF- $\alpha$ in peripheral blood of the female soccer players in response to exercise.

\begin{tabular}{|c|c|c|c|c|c|c|}
\hline \multirow[b]{2}{*}{ Gene } & \multicolumn{3}{|c|}{ Post-exercise } & \multicolumn{3}{|c|}{ Recovery } \\
\hline & Expression & SE & $P$ & Expression & SE & $P$ \\
\hline IL1B & 1.17 & $0.009-132.4$ & 0.889 & 2.41 & $0.04-110.2$ & 0.420 \\
\hline IL6 & 1.93 & $0.02-196.8$ & 0.580 & 15.1 & $0.167-1745.2$ & 0.030 \\
\hline TNFA & 1.09 & $0.004-177.2$ & 0.940 & 5.75 & $0.02-481.7$ & 0.162 \\
\hline
\end{tabular}

Post-exercise - immediately after finished exercise test vs. pre-exercise;

Recovery - 15 minutes after exercise test vs. post-exercise. SE - standard error interval; $P$ - probability; Expression of reference gene $G A P D H=1.00$.

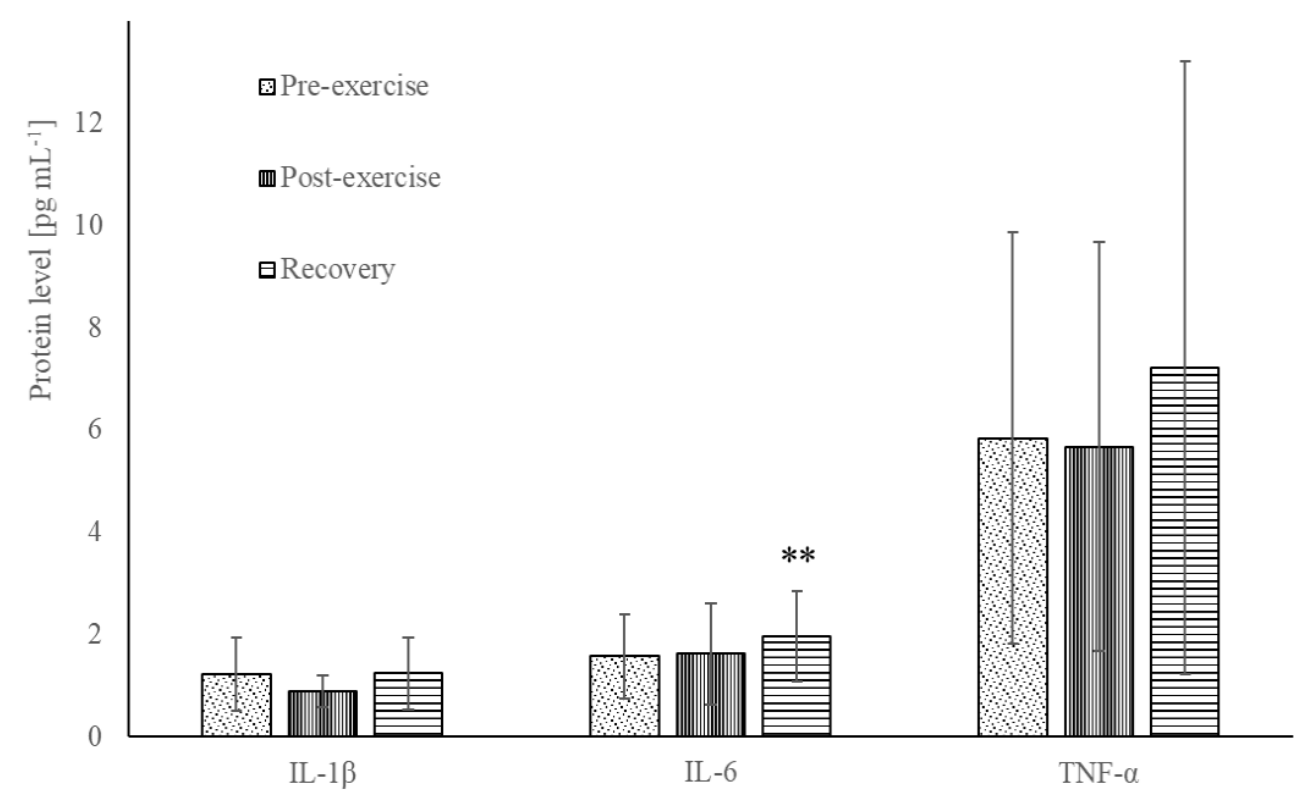

Figure 1

Cytokine concentrations in blood serum of the female soccer players (mean \pm SD) Pre-

exercise - immediately before exercise; Post-exercise - immediately after exercise; recovery -15 minutes after cessation of exercise; $S D$ - standard deviation. ${ }^{* *} p<0.005$ indicates statistically significant differences between pre-exercise and recovery values. 
Table 3

Serum hormone concentrations in response to the graded exercise of female soccer players (mean \pm SD).

\begin{tabular}{|c|c|c|c|c|c|c|c|c|}
\hline \multirow{2}{*}{ Variables } & \multicolumn{3}{|c|}{ Hormone kinetics } & \multicolumn{2}{|c|}{ Effect of exercise } & \multicolumn{3}{|c|}{ Post hock } \\
\hline & $\begin{array}{l}\text { Pre-exercise } \\
\text { (A) }\end{array}$ & $\begin{array}{l}\text { Post-exercise } \\
\text { (B) }\end{array}$ & $\begin{array}{l}\text { Recovery } \\
\text { (C) }\end{array}$ & $\mathrm{F}$ & $p$ & $\begin{array}{l}\text { Post hoc } \\
\text { A vs B }\end{array}$ & $\begin{array}{l}\text { Post hoc } \\
\text { A vs C }\end{array}$ & $\begin{array}{l}\text { Post } \\
\text { hoc B vs } \\
\text { C }\end{array}$ \\
\hline $\mathrm{T}[\mathrm{nmol} / \mathrm{l}]$ & $3.8(1.7)$ & $4.3(1.5)$ & $4.3(1.4)$ & 1.36 & 0.27 & 0.52 & 0.46 & 1.00 \\
\hline $\mathrm{C}[\mathrm{nmol} / \mathrm{l}]$ & $457.0(163.6)$ & $571.0(145.6)$ & $609.2(206.7)$ & 8.15 & 0.001 & 0.02 & 0.001 & 1.00 \\
\hline $\mathrm{T} / \mathrm{C}^{*} 100$ & $0.7(0.3)$ & $1.0(0.4)$ & $0.8(0.4)$ & 9.15 & 0.001 & 0.001 & 1.00 & 0.01 \\
\hline $\mathrm{HGH}[\mu \mathrm{IU} / 1]$ & $16.1(13.9)$ & $52.5(27.6)$ & $45.1(32.8)$ & 16.29 & 0.000 & 0.000 & 0.000 & 0.85 \\
\hline IGF-1 [ng/ml] & $236.6(54.6)$ & $250.4(70.2)$ & $263.7(78.7)$ & 2.51 & 0.10 & 0.78 & 0.10 & 0.84 \\
\hline IGFBP-3 [ng/ml] & $2722.5(979.0)$ & 3033.7 (1255.0) & $2573.0(896.7)$ & 1.44 & 0.25 & 0.81 & 1.00 & 0.32 \\
\hline freeT $[\mathrm{pg} / \mathrm{ml}]$ & $1.6(0.8)$ & $1.6(0.7)$ & $1.7(0.7)$ & 1.80 & 0.18 & 1.00 & 0.21 & 0.68 \\
\hline
\end{tabular}

T-testosterone, C - Cortisol, hGH - human growth hormone, IGF-1 - insulin like growth hormone, IGFBP - 3 insulin like growth hormone binding protein -3.

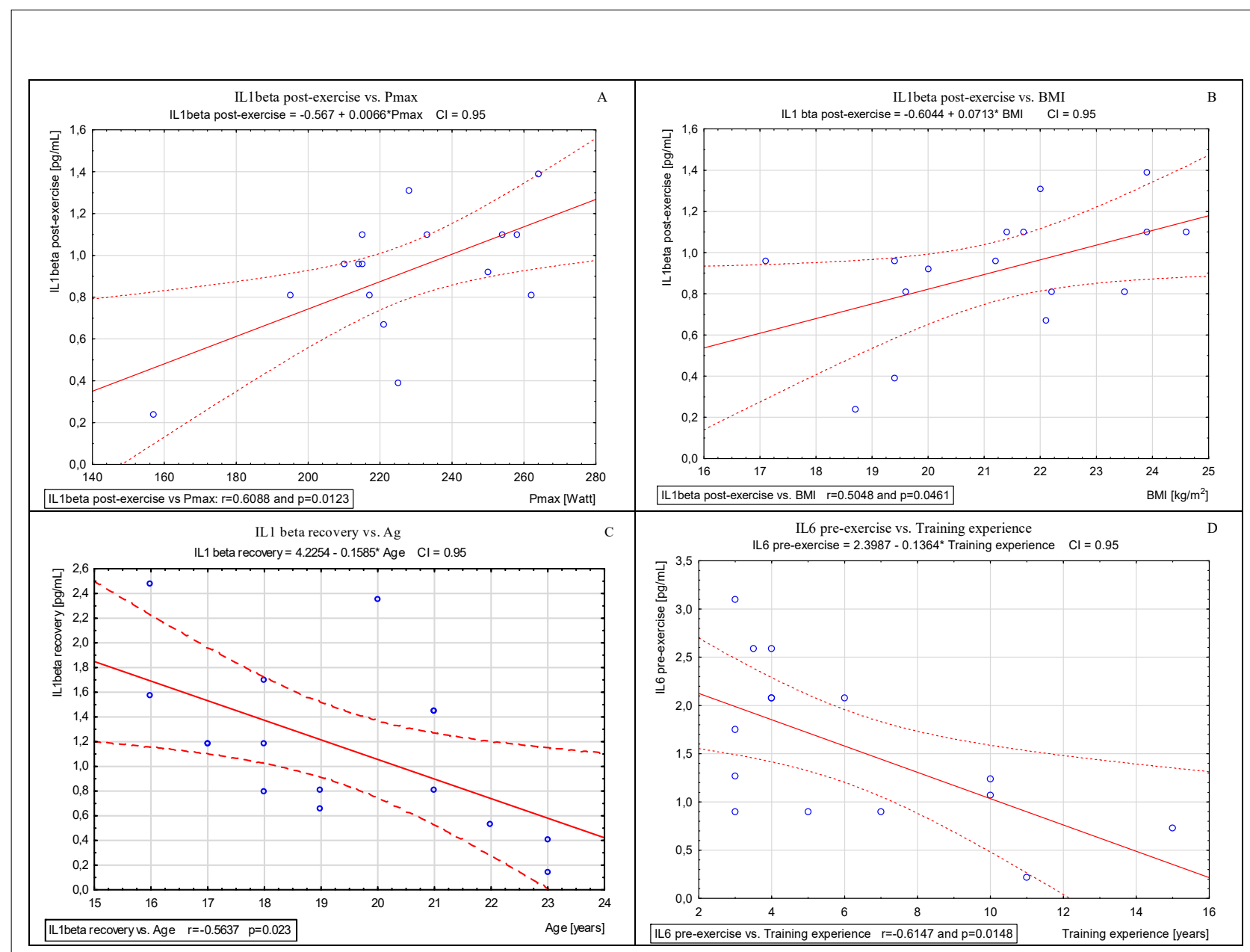

Figure 2

Correlation between serum concentration of $I L-1 \beta$ post-exercise and maximal power $(a)$ and body mass index (b); recovery IL-1 $\beta$ and age (c), and pre-exercise IL-6 and training experience of the female soccer players $(d)$. 


\section{Discussion}

Our findings confirm previous reports that the strain of exercise elicited differences in IL6 gene expression, as well as protein level during the recovery period after intense exercise of trained athletes. It is well-known that exerciseinduced expression of IL- $1 \beta$ and TNF- $\alpha$ is associated with higher transcriptional activity of IL-6 (Gjevestad et al., 2015). It should be stated that the intense treadmill exercise to volitional exhaustion elicited a time-dependent increase of IL-6 during recovery, but did not alter serum IL$1 \beta$ and TNF- $\alpha$ concentration. Previous studies support the findings that exercise which induces gene expression of inflammatory markers (acute phase cytokines) and their signaling pathways may constitute a sensitive tool to characterize the early effects of exercise on immune regulation (Pedersen and Hoffman-Goetz, 2000; RadomAizik et al., 2009) and adaptive processes during exercise (Ostrowski et al., 1999; Gillum et al., 2011; Roli et al., 2018). Physical stress causes the deregulation of muscle homeostasis and fiber integrity. The immune system is also directly involved in several repair and regeneration processes after exercise. IL- $1 \beta$ and TNF- $\alpha$ are secreted during injuries and infections, whereas interleukin 6 is generally synthesized after the initial synthesis of these cytokines e.g. as a result of the contracting muscles (Walsh et al., 2011; Reihmane and Dela, 2014). IL-6 also contributes to metabolic substrate availability and may be involved in an increase of central fatigue, overtraining and hormone responses to training (Smith, 2000; deRocha et al., 2019).

There are limited data regarding the mechanism that determines the differences in women's immune system. To our knowledge, this study is the first to examine gene expression and protein concentrations of the pro-inflammatory cytokines in elite female soccer players in response to endocrine factors during exercise. In this study, no significant changes in IL- $1 \beta$ and TNF- $\alpha$ gene expression and protein concentrations were observed in response to the intense exercise. Thus, our results may indicate no signs of inflammation or tissue damage. Similar to our study, Ullum et al. (1994) did not observe any effect of exercise on IL-1 $\beta$ and TNF- $\alpha$ gene expression in healthy moderately trained individuals. A significant increase of IL-6 levels and leukocyte count with no differences in IL-1 $\beta$, and TNF- $\alpha$ levels and gene expression of IL- $1 \beta$ and TNF- $\alpha$ in blood mononuclear cells were also reported (Moldoveanu et al., 2000; deRocha et al., 2019).

In our findings a negative correlation was observed between the level of pre-exercise IL-6 and training status. A number of factors such as individual genetic variability, different exercise protocols, age and gender of the athletes, as well as other lifestyle factors influence the effects of post-exercise inflammatory processes (Abbasi et al., 2013; Anderssson et al., 2010; Radom-Aizik et al., 2009). Our results confirm that there exists a significant positive correlation between exercise intensity and IL-1 $\beta$ levels. Higher transcriptional activity of IL-1 $\beta$ may be associated with the exercise-induced increase in gene and protein level of IL-6. Our results showed that training experience of the players has an significant effect on post-exercise serum IL-6 concentration; the longer the training experience the lower the serum IL-6. However, post-exercise IL-1 $\beta$ level increases in response to higher body mass index and lower post-exercise free testosterone levels. It should be concluded that these relations may depend on the gender or individual performance level and need a more extensive explanation.

In our study, the female soccer players demonstrated higher serum cortisol levels recorded in response to the graded exercise and significantly higher serum $\mathrm{T} / \mathrm{C}$ ratio compared to pre-exercise levels. Cortisol is the main human glucocorticoid secreted from the adrenal cortex in response to physical and psychological stress (Meckel et al., 2011). Exercise induced cortisol may be responsible for anti-inflammatory properties and inhibition of amino acid uptake by skeletal muscle, lower protein synthesis and catabolic effects of exercise (Popovic et al., 2019). Intensive exercise and training represents a strong stimulus for cortisol response and may induce lower testosterone secretion. On the contrary, an increased concentration of testosterone is vital for exercise metabolism (e.g.: the synthesis of structural proteins, protects them against catabolism, and supports the restoration of glycogen stores after exercise (Anderson et al., 2016). At rest, approximately $99 \%$ of total testosterone is bound with sex hormone-binding 
globulin and only $1 \%$ of $\mathrm{T}$ is free. Therefore, the increased concentration of freeT levels in response to exercise may stimulate muscle hypertrophy in training related conditions. While cortisol secretion can be used as an indicator of physical stress and a catabolic marker, the testosterone to cortisol ratio $(\mathrm{T} / \mathrm{C})$ may represent a physiological indicator of anabolic/catabolic disbalance, fatigue and overreaching in athletes (Lac et al., 2000; Olivera et al., 2009).

Our study revealed higher post-exercise serum $\mathrm{T} / \mathrm{C}$ ratio in our female soccer players compared to pre-exercise values, suggesting that $\mathrm{T}$ may be involved in beneficial adaptation to exercise and muscle hypertrophy. The positive correlation observed between total testosterone and freeT and a negative correlation between freeT and IL1 $\beta$ may suggests that the hypertrophic effect observed in our athletes was stimulated by higher affinity of free testosterone lower this cytokine expression. This could be supported by previous data which have shown that endurance training may result in upregulation of androgen receptors, thereby increasing the effectiveness of testosterone action (Sato et al., 2016; Zeng et al., 2017).

Although previous studies identified a significant stimulatory effect of exercise (Schwarz et al., 1996; Gregory et al., 2013; Hackney et al.,
2016) and training of female athletes (Roli et al., 2018) on serum IGF-1 levels, our data showed no significant differences in either IGF-1 and IGFBP-3 in response to graded exercise. In the present study, post-exercise cortisol levels seem to stimulate higher IGF-1 levels, whereas higher T/C levels correspond to lower hGH and IGF-1 secretion.

There are limited data regarding the mechanism that determines the anabolic hormone function in response to exercise. It seems that exercise induces a lower concentration of cortisol and higher testosterone bioavailability in female athletes with a greater performance capacity.

\section{Conclusions}

In summary, the exercise-induced inflammatory reaction was only reflected by a significant increase in gene and protein level of IL6. A novelty of this study is the finding that gene expression and serum concentrations of IL1 $\beta$ are inversely associated with age and testosterone availability in female soccer players. Changes in cytokine levels and their mutual relationships may be indicative of physiological adaptation to intense exercise and its benefits to health, and compensatory attempt to restore immune homeostasis in trained female soccer players.

\section{Acknowledgements}

The study was supported by the Medical University of Silesia (KNW-1-023/K/4/0/2/14/15; KNW-1024/N/5/0; KNW-1-013/K/7/0) and The Jerzy Kukuczka Academy of Physical Education.

\section{References}

Abbasi A, Fehrenbach E, Hauth M, Walter M, Hudemann J, Wank V, Niess AM, Northoff H. Changes in spontaneous and LPS-induced ex vivo cytokine production and mRNA expression in male and female athletes following prolonged exhaustive exercise. Exerc Immunol Rev, 2013; 19: 8-28

Anderson T, Lane AR, Hackney AC. Cortisol and testosterone dynamics following exhaustive endurance exercise. Eur J Appl Physio, 2016; 116(8): 1503-9

Andersson H, Bohn SK, Raastad T, Paulsen G, Blomhoff R, Kadi F. Differences in the inflammatory plasma cytokine response following two elite female soccer games separated by a 72-h recovery. Scand J Med Sci Sports, 2010; 20(5): 740-747

Bizzini M, Dvorak J. FIFA 11+: an effective programme to prevent football injuries in various player groups worldwide-a narrative review. Br J Sports Med, 2015; 49(9): 577-579

Chmura P, Podgórski T, Konefał M, Rokita A, Chmura J, Andrzejewski M. Endocrine responses to various 1 x 1 small-sided games in youth soccer players. Int J Envirom Res Public Health, 2019; 16: 4974; doi:10.3390/ijerph16244974

Chomczynski P, Sacchi N. Single-step method of RNA isolation by acid guanidinium thiocyanate-phenolchloroform extraction. Anal Biochem, 1987; 162(1): 156-159

Copeland JL, Heggie L. IGF-I and IGFBP-3 during continuous and interval exercise. Int J Sports Med, 2008; 29: 182-187 
da Rocha AL, Pinto AP, Kohama EB, Pauli JR, de Moura LP, Cintra DE, Ropelle ER, da Silva ASR. The proinflammatory effects of chronic excessive exercise. Cytokine, 2019; 119; 57-61

Edwards DA, Casto KV. Women's intercollegiate athletic competition: cortisol, testosterone, and the dualhormone hypothesis as it relates to status among teammates. Hormones and Behavior, 2013; 64: 153-160

Gillum TL., Kuennen MR, Schneider S, Moseley P. A review of sex differences in immune function after aerobic exercise. Exerc Immunol Rev, 2011; 17: 104-121

Giraldo E., Hinchado M., Garcia J., Ortega E. Influence of gender and oral contraceptives intake on innate and inflammatory response. Role of neuroendocrine factors. Molecular and Cellular Biochemistry, 2008; 313,147

Gjevestad GO, Holven KB, Ulven SM. Effects of exercise on gene expression of inflammatory markers in human peripheral blood cells: A systematic review. Curr Cardiovasc Risk Rep, 2015; 9(7): 34

Gregory BA, Spiering BA, Alemany JA, Tuckow AP, Rarick KR, Staab JS, Hatfield DL, Kraemer WJ, Maresh $\mathrm{CM}$, Nindl BC. Exercise-induced insulin-like growth factor I system concentrations after training in women. Med Sci Sports Exerc, 2013; 45 (3): 420-428

Hackney AC, Davis HC, Lane AR. Growth hormone-insulin-like growth factor axis, thyroid axis, prolactin, and exercise. Front Horm Res, 2016; 47: 1-11

Jürimäe J, Maestu J, Jürimäe T, Mangus B, von Duvillard SP. Peripheral signals of energy homeostasis as possible markers of training stress in athletes: a review. Metabolism, 2011; 60(3): 335-350

Lac G, Berthon P. Changes in cortisol and testosterone levels and $\mathrm{T} / \mathrm{C}$ ratio during an endurance competition and recovery. J Sports Med Phys Fitness, 2000; 40(2): 139-144

Larsen B, Cox JA, Quinn K, Fisher R, Minahan C. Immune response in women during exercise in the heat: A spotlight on oral contraception. J Sports Sci Med, 2018; 17(2): 229-236

Meckel Y, Nemet D, Bar-Sela S, Radom-Aizik S, Cooper DM, Sagiv M, Eliakim A. Hormonal and inflammatory responses to different types of sprint interval training. J Strength Cond Res, 2011; 25(8): 2161-2169

Moldoveanu AI, Shephard RJ, Shek PN. Exercise elevates plasma levels but not gene expression of IL-1beta, IL-6, and TNF-alpha in blood mononuclear cells. J Appl Physiol, 2000; 89(4): 1499-1504

Oliveria T, Gouveia MJ, Oliveira RF. Testosterone responsiveness to winning and losing experiences in female soccer players. Psychoneuroendocrinology, 2009; 34: 1056-1064

Ostrowski K, Rohde T, Asp S, Schjerling P, Pedersen BK. Pro- and anti-inflammatory cytokine balance in strenuous exercise in humans. J Physiol, 1999; 515(Pt1): 287-291

Ostrowski K, Schjerling P, Pedersen BK. Physical activity and plasma interleukin-6 in humans - effect of intensity of exercise. Eur J Appl Physiol, 2000; 83(6) 512-515

Pedersen BK, Febbraio MA. Muscle as an endocrine organ: focus on muscle-derived interleukin-6. Physiol Rev, 2008; 88(4): 1379-1406

Pedersen BK, Hoffman-Goetz L. Exercise and the immune system: regulation, integration, and adaptation. Physiol Rev 2000; 80(3): 1055-1081

Petersen AMW, Pedersen BK. The role of IL-6 in mediating the anti-inflammatory effects of exercise. J Physiol Pharmacol, 2006; 57(10): 43-51

Pfaffl MW, Horgan GW, Dempfle L. Relative expression software tool (REST) for group-wise comparison and statistical analysis of relative expression results in real-time PCR. Nucleic Acids Res, 2002; 30(9): e36

Popovic B, Popovic D, Macut D, Antic I, Isailovic T, Ognjanovic S, Bogavac T. Acute response to endurance exercise stress: focus on catabolic/anabolic interplay between cortisol, testosterone, and sex hormone binding globulin in professional athletes. J Med Biochem, 2019; 38(1): 6-12

Radom-Aizik S, Zaldivar FJ, Leu S-Y, Cooper DM. A brief bout of exercise alters gene expression and distinct gene pathways in peripheral blood mononuclear cells of early- and late-pubertal females. J Appl Physiol, 2009; 107(1): 168-175

Reihmane D, Dela F. Interleukin-6: possible biological roles during exercise. Eur J Sport Sci, 2014; 14(3): 242250

Roli L, DeVincentis S, Rocchi LBM, Trenti T, DeSantis CM, et al. Testosterone, cortisol, hGH, and IGF-1 levels in an Italian female elite volleyball team. Health Science Reports, $2018 \mathrm{https} / / \mathrm{doi} .0 r g / 10.1002 / \mathrm{hsr} 2.32$

Rowell AE, Aughey RJ, Hopkins WG, Esmaeili A., Lazarus BH, Cormack SJ. Effects of training and competition load on neuromuscular recovery, testosterone, cortisol, and match performance during a 
season of professional football. Frontiers in Physiology, 2018; 9: doi:10.3389/fphys.2018.00668

Sato J, Iemitsu M, Katayama K, Ishida K, Kanao Y, Saito M. Responses of sex steroid hormones to different intensities of exercise in endurance athletes. Exp Physiol, 2016; 101(1): 168-175

Scheller J, Chalaris A, Schmidt-Arras D, Rose-John S. The pro- and anti-inflammatory properties of the cytokine interleukin-6. Biochem Biophys Acta, 2011; 1813(5): 878-888

Schuurs A, Verheul H. Effects of gender and sex steroids on the immune response. Journal of Steroid Biochemistry, 1990; 35, 157-172

Smith LL, Cytokine hypothesis of overtraining: a physiological adaptation to excessive stress? Med Sci Sports Exerc, 2000; 32 (2): 317-331

Soligard T, Myklebust G, Steffen K, Holme I, Silvers H, Bizzini M, Junge A, Dvorak J, Bahr R, Andersen TE. Comprehensive warm-up programme to prevent injuries in young female footballers: cluster randomised controlled trial. BMJ, 2008; 337: a2469

Souglis AG, Papapanagiotou A, Bogdanis GC, Travlos AK, Apostolidis NG, Geladas ND. Comparison of inflammatory responses to a soccer match between elite male and female players. J Strength Cond Res, 2015; 29(5): 1227-1233

Ullum H, Haahr PM, Diamant M, Palmo J, Halkjaer-Kristensen J, Pedersen BK. Bicycle exercise enhances plasma IL-6 but does not change IL-1 alpha, IL-1 beta, IL-6, or TNF-alpha pre-mRNA in BMNC. J Appl Physiol, 1994; 77(1): 93-97

Walsh NP, Gleeson M, Shephard RJ, Gleeson M, Woods JA, Bishop NC, Fleshner M, Green C, Pedersen BK, Hoffman-Goetz L, Rogers CJ, Northoff H, Abbasi A, Simon P. Position statement. Part one: Immune function and exercise. Exerc Immunol Rev, 2011; 17: 6-63

Zeng F, Zhao H, Liao J. Androgen interacts with exercise through the mTOR pathway to induce skeletal muscle hypertrophy. Biol Sport, 2017; 34(4): 313-321

Żebrowska A, Gąsior Z, Langfort J. Serum IGF-I and hormonal responses to incremental exercise in athletes with and without left ventricular hypertrophy. J Sports Sci Med, 2009; 8: 67-76

\section{Corresponding author:}

\section{Aleksandra Żebrowska}

Institute of Sport Sciences, Academy of Physical Education,

Mikołowska Street 72a, 40-065 Katowice, Poland

Phone: +48608418581

E-mail: a.żebrowska@awf.katowice.pl 